\title{
La Bula de la Santa Cruzada... ¿un remedio para sanar el alma?
}

\author{
Ma. Concepción Lugo Olín \\ DIRECCIÓN DE ESTUDIOS HISTÓRICOS-INAH
}

En este artículo se estudia el papel que jugó, en la sociedad virreinal, la Bula de la Santa Cruzada de 1578 a 1821, no sólo como una de las prácticas preparatorias para la muerte, sino como el instrumento que manejó la Iglesia de la Contrarreforma para propagar las distintas creencias $y$ prácticas religiosas avaladas por el Concilio de Trento.

$\mathbf{L}$ a Bula de la Santa Cruzada, que se constituyó, desde sus orígenes medievales, como un valioso instrumento para salvar el alma, era un documento apostólico por el cual el Sumo Pontífice, máxima autoridad del mundo cristiano, otorgaba, por el término de un año, diferentes indulgencias a quienes participaran en la guerra contra los infieles, ya fuera personalmente, costeando la participación de otro, o ayudando con alguna limosna a cubrir los cuantiosos gastos que generaron las dos guerras consideradas santas: las Cruzadas y la Reconquista española. ${ }^{1}$
Con la expedición de este documento, además de tener un contingente militar asegurado, la Iglesia no sólo avalaba la intervención de sus participantes en la defensa de la cristiandad, sino que les concedía nada menos que el perdón de sus pecados; por tal motivo numerosos homicidas, perjuros, adúlteros, raptores y otros grandes malhechores se ponían gustosos al servicio de dicha causa esperando encontrar, en esas luchas, el

${ }^{1}$ Le Goff, Baja, 1974 p. 131; Weckmann, Herencia, 1984, vol. 1, p. 21. 
medio adecuado de alcanzar el "Reino de los Cielos". 2

De esta forma, a la prédica de la primera Cruzada, hecha por Urbano II en 1096, siguieron otras más hasta introducirse la bula en España, hacia los siglos XII-XIII, cuando el papa concedió a los Reyes Católicos el derecho de expedir la bula para ayudarse en la lucha contra los moros. Una vez finiquitadas estas campañas con la victoria cristiana, los monarcas europeos seguirían gozando de este beneficio y destinando los fondos a costear las guerras contra los turcos y otros pueblos considerados, por los cristianos, como infieles. Más tarde, entre 1573 y 1578, el pontífice Gregorio XIII extendería el privilegio de la Bula al nuevo mundo, cuya conquista cerraría la era medieval con el inicio del Renacimiento. ${ }^{3}$

Desde su introducción en Nueva España, las bulas se considerarían instrumentos coadyuvantes al bien morir, y serían destinados, en su conjunto, a conservar la salud del alma, y a ayudar a los fieles a mantener su vida pura al liberarlos del pecado, así como al servicio y a la unión con Dios mediante el fomento de la fe y el ejercicio de diversas obras pías. Se encaminaban, asimismo, a fortalecer el espíritu y a prepararlo para entablar otra lucha, tanto o más desigual que aquellas guerras santas, en contra de los mortales enemigos de la gracia, como eran el pecado y la tentación. Con el triunfo en este combate, los fieles lograrían vencer a la muerte y conquis-

\footnotetext{
${ }^{2}$ Le Goff, Baja, p. 126.

${ }^{3}$ Weckmann, Herencia, vol. 1, p. 385.
}

tar la Jerusalén Celestial mediante la salvación de sus almas. ${ }^{4}$

La venta por la Iglesia de este importante instrumento de perdón, se llevaba a cabo, en Nueva España, cada dos años. Un religioso con el cargo de comisario de Cruzada, apoyado en unos manuales conocidos como Explicación de la Bula de la Santa Cru$\mathrm{zada}^{5}$ informaba a la feligresía sobre el funcionamiento, el sentido y los alcances del documento, al tiempo que exaltaba sus invaluables beneficios en medio de una solemne y ostentosa ceremonia organizada con el deliberado propósito de deslumbrar a los vasallos novohispanos y asegurar la venta. $^{6}$

Las dispensas concedidas por la Bula pronto se difundieron por todas las parroquias y curatos del virreinato

${ }^{4}$ Venegas, Agonía, 1565, f. cVIII; Carrillo, Explicación, 1602, pp. 2-3; Crasset, Dulce, 1788.

${ }^{5}$ En los fondos conventuales de nuestro país se localizan numerosos manuales sobre la Explicación de la Bula o Llaves del Reino de los Cielos como también se los conocía. Unos son importados, en tanto que otros son novohis- * panos, pero todos fueron redactados invariablemente por religiosos. La publicación de dichos manuales que bien podrían constituir verdaderos catálogos, corrió paralela a los años de la vigencia de la Bula: 1573-1821. En ellos se pueden distinguir tres partes fundamentales. Una de carácter introductorio que consiste en la historia del documento desde sus orígenes hasta la autorización de su venta en el nuevo mundo. Otra sección dogmática que se encargaba de informar a los fieles sobre la finalidad, funcionamiento y beneficios de la Bula; en la última parte se los orientaba sobre las prácticas que debían ejecitar para obtener esos beneficios, así como el dónde, el cuándo y el cómo realizarlas.

${ }^{6}$ Mansutti, Catálogo, 1979, p. III. 
para llegar, en el siglo XVIII, hasta los pueblos de indios. Su demanda corrió paralela a la de esos difíciles siglos coloniales en los que numerosas calamidades provocadas por la peste, el hambre y la guerra, hicieron de la muerte un hecho constante, cotidiano y presente. Más tarde, durante el barroco, por las características própias de la época, esta venta de perdón alcanzô un auge inusitado, pues en ese tiempo la muerte se convirtió en una verdadera obsesión que normó la vida de esa sociedad sacralizada de entonces, para desaparecer por completo con la supresión de la Bula en 1821, en los albores del México independiente.

Con esta valiosa llave que abriría el mismísmo Reino de los Cielos, y sin la cual ninguna indulgencia tenía validez, la Iglesia Católica de la Contrarreforma no sólo pudo reunir cuantiosas sumas para la propagación de la fe, sino que tuvo también en sus manos una poderosa arma que hábilmente supo manejar para promover, defender y justificar diversas normas $y$ creencias confirmadas en el Concilio Ecuménico de Trento y, de manera especial, aquellas que eran severamente atacadas por los reformadores protestantes.

La Bula constituía en sí misma un reconocimiento directo a la autoridad del pontífice y una defensa tenaz de

${ }^{7}$ Carreño, Cedulario, 1947, pp. 287, 358, 362, 461, 462, 515; Recopilación, 1973, vol. 1, libro 1, título XX, pp. 103-104. Véase también AGN, ramo de Bulas y Santa Cruzada, años $1647,1669,1743,1771,1789,1793$ y 1805; Fonte, "Decreto", en La Abeja Poblana, t. II, núm. 4, 17 de diciembre de 1821 . las criticadísimas indulgencias. Sirvió, al mismo tiempo, como un medio para fundamentar creencias tales como la existencia del purgatorio y justificar el ejercicio de diversas prácticas religiosas igualmente atacadas, como las devociones marianas, la devoción a los santos y mártires de la fe, la recepción de los sacramentos de la confesión, de la comunión y de la extremaunción, así como la asistencia a misa, prácticas sin las cuales, a la Iglesia le resultaba imposible ejercer sus privilegios. $^{8}$

La importancia de ejercitar estas prácticas radicaba, según la Iglesia, en que eran las armas con que la Santa Madre Iglesia dotaba a sus hijos para fortalecer su espíritu, y no sólo para combatir sino también para vencer al pecado y, así, evitar la muerte del alma o condenación eterna.

De esta manera las devociones marianas garantizaban la presencia de la Virgen María en el momento de la muerte de sus hijos que se iban a salvar; mientras que la veneración a los santos y mártires de la fe aseguraba la salvación en tanto que, esos seres en gracia, además de ser eficientes intercesores entre el hombre y la divinidad, eran la representación misma de la victoria contra el pecado y la carne: por ello, su ejemplo serviría para alejar a los fieles del mal, al tiempo que serían modelo y guía en la preparación para la muerte.

La confesión es el sacramento por medio del cual Cristo limpia con su sangre las almas; el de la comunión

${ }^{8}$ Salazar, Llave, 1738 , pp. 10-11. 
da vida porque Cristo prometió vida eterna a aquel que tomara su cuerpo y bebiera su sangre. La extremaunción ocupa un lugar especial por ser el último sacramento con que la Santa Madre Iglesia ayudaba a sus hijos a librar el combate de la agonía por medio de la bendición de boca, oídos, nariz, manos y pies, partes del cuerpo consideradas como las puertas de entrada del pecado; y por último, asistir a misa equivalía a presenciar la representación de la muerte del hijo de Dios, pues no podía morir en pecado el ser humano por quien el Señor había ofrecido tantas veces su vida. ${ }^{9}$

No menos importantes eran el ayuno, porque representaba el castigo corporal; y la limosna con la que, además de ayudar en la lucha contra los infieles, se daba cumplimiento a una obra de misericordia. Contaba también la visita a cinco altares por simbolizar éstos las cinco llagas del cuerpo de Cristo con que el Señor había redimido los pecados cometidos por los hombres a través de sus cinco sentidos y, por último, la oración ofrecida por el triunfo del cristianismo sobre los infieles. ${ }^{10}$

La explicación de la Bula descansaba en el dogma de la Comunión de los Santos, mismo que partía de la existencia de una sola Iglesia, la cual, a semejanza de un cuerpo, contaba con distintos miembros que, al trabajar unidos, alcanzarían esa comunión. De esta manera, la Iglesia Triunfante en que se encontraban Cristo, la Virgen y los santos y mártires de la fe, al

\footnotetext{
${ }^{9}$ Crasset, Dulce, 1788, pp. 221-240.

${ }^{10}$ Guijarro, Buen, 1792, vol. 2, p. 3.
}

lado de los justos y gozando de vida eterna, era la poseedora de un inagotable tesoro de perdón; éste estaba compuesto por los méritos y sacrificios de los seres en gracia, cuyas abundantes obras, al ser ofrecidas por el bien común de la Iglesia, habían alcanzado para pagar las deudas de todos los fieles vivos y difuntos; por ello, éstas representaban el manantial que surtía a esa, no menos inagotable fuente de indulgencias, que era la Bula de la Santa Cruzada. ${ }^{11}$

La tarea de la Iglesia Militante, compuesta por los fieles de la tierra, era la de luchar, desde este Valle de Lágrimas, y con el auxilio de estos méritos, por la salvación de sus propias almas; y al mismo tiempo, ayudar, mediante el ejercicio de las buenas obras, a disminuir las penas de aquellas otras almas del purgatorio que integraban la Iglesia Purgante, almas que, una vez liberadas y en señal de gratitud, intercederían ante Dios a su llegada a la Jerusalén Celestial para lograr el perdón de los pecadores pertenecientes a la Iglesia Militante. ${ }^{12}$

Este trabajo, unido a la inmensidad de aquel tesoro de indulgencias, servían para fundamentar el carácter universal de la Bula, cuyos beneficios podrían alcanzar tanto hombres como mujeres, nobles y plebeyos, religiosos o laicos ya fueran vivos o fieles difuntos, entre los que existieron, sin lugar a dudas, numerosos pecadores necesitados de su ayuda.

Con el fin de obtener mayores ganancias en la venta de estas dispensas

\footnotetext{
${ }^{11}$ Calzada, Tratado, 1838, vol. 1, pp. 3-4.

${ }^{12}$ Ibid.
} 
capaces de lavar las peores atrocidades, exceptuando la herejía, se dividieron en cuatro secciones diferentes, mismas que podían adquirirse en su totalidad o bien en partes, dependiendo de las características y de las culpas de los compradores. Los apreciados beneficios de estos verdaderos seguros de vida eterna estaban con'tenidos en la Bula de Vivos, la de Lactricinios, o de Composición, y la Bula de Difuntos. Entre los requisitos indispensables para obtener las tres primeras, estaba el de hallarse en gracia de Dios, pues sus ventajas eran personales $y$, por tanto, aplicables solamente a la salvación del alma del comprador. Su enorme demanda radicaba en que, más que indulgencias, otorgaban a sus poseedores una serie de permisos y facilidades negadas a otros para conseguir bienes materiales y obtener dispensas difíciles o imposibles, purificar el alma, negociar una reconciliación con Dios y preservar a los fieles, desde esta vida, de las temibles y casi infernales penas del purgatorio. ${ }^{13}$

En cambio, para adquirir la Bula de Difuntos no era necesario estar en gracia, pues como su objeto era rescatar del purgatorio el alma de otro, bastaba sólo con la buena voluntad, amén de pagar la suma convenida.

Múltiples eran las indulgencias otorgadas por la Bula de Vivos, cuyo

\footnotetext{
${ }^{13}$ De hecho, el requisito de estar en gracia de Dios, en la práctica, no era tan indispensable, puesto que en los mismos manuales se estipulaba que bastaba sólo con pagar la cantidad determinada. Rodríguez, Explicación, 1594, p. 56; Anónimo, Explicación, 1788, p. 69.
}

costo fluctuaba, en el siglo XVII, entre 10 y 20 pesos de oro, atendiendo no a la gravedad de las faltas, sino al estrato social de los demandantes. ${ }^{14}$ Una de estas dispensas era la que amparaba la Bula de la Cena, así denominada porque se publicaba el Jueves Santo, día en que se conmemora la última. cena del Señor con sus discípulos. Su compra facilitaba la absolución de aquellas culpas, cuyo perdón, por su gravedad, era reservado a los severos obispos, a los temidos inquisidores o bien al mismísimo pontífice. Sin embargo, con esta Bula el pecador podía también acudir a cualquier confesor de su confianza en busca de la anhelada absolución. El documento servía asimismo a los justos para rebajar las penas debidas por sus pecados; mientras que a los excomulgados, quienes por sus faltas eran excluidos del cuerpo de la Iglesia, se les garantizaba con él su restitución inmediata a la comunidad de fieles. ${ }^{15}$

En ese tiempo en que la vida y la muerte giraban en torno a la religión y a la salvación del alma, había algunas culpas que, por su gravedad, se castigaban privando al pecador de la recepción de los sacramentos de la confesión, de la comunión y de la extremaunción, así como de la asistencia a misa y del entierro en lugares sagrados, ya que estas prácticas eran -como hemos visto- algunos de los medios que, supuestamente, los ayudarían a mantener la salud del alma.

\footnotetext{
${ }^{14}$ Fernández, Tasación, 1700, 1 hoja.

${ }^{15}$ Anónimo, Explicación, 1978, pp. 5, 33,
} 37 y 38. 
El periodo que, transcurría entre el castigo y el perdón se conocía como "tiempo de entredicho", mismo que la Bula tenía el poder de nulificar, devolviendo esas armas al pecador para que con ellas se incorporara nuevamente a luchar por la salud de su alma.

La Bula de Vivos concedía, támbién, la disminución y hasta la suspensión de múltiples promesas, penitencias y votos -exceptuando el de castidad- cuyo rigor o duración dificultaba y aun imposibilitaba su cumplimiento. Como si esto fuera poco, los favores de la Bula se extendían hasta la propia agonía, durante la cual se concedía al moribundo la indulgencia plenaria, es decir, el indulto de todas sus penas; en este perdón se resumían todos los favores de la Bula de Vivos, de ahí la importancia de contar con ese fabuloso instrumento en el inevitable trance de la muerte. ${ }^{16}$

Un documento en el que consta esa absolución total que garantizaba a sus poseedores el pase directo a la gloria dice a la letra:

[...] Yo te absuelvo de todas las censuras de excomunión $[\ldots]$ de la suspensión o entredicho [...] de todas las censuras y penas en que por cualquier causa hayas incurrido, aunque la absolución sea reservada a la Santa Sede. [...] te absuelvo de todos tus pecados, crímenes y excesos $[\ldots]$ y otórgote indulgencia plenaria y remisión cumplida de todos tus pecados, ahora y en cualquier tiempo confesados, olvidados o ignorados y de las penas que por ellos eres obligado a padecer en el

${ }^{16}$ Ibid., pp. 37, 47, 69, 79, 88. purgatorio $[\ldots]$ y, si de esta enfermedad en que estás, Dios, por su misericordia, te librare, séate reservada esta indulgencia para el verdadero artículo de muerte $[\ldots]^{17}$

La Bula de Lactricinios se contaba, también, entre esos contradictorios y aun arbitrarios remedios para la salud del alma, cuya venta tenía especial demanda entre los siempre golosos miembros del clero y otros no menos tragones feligreses, quienes pagaban gustosos la suma que, en el siglo XVIII, iba de uno a cuatro pesos oro, con tal de poder disfrutar de un buen número de viandas, deliciosas para el paladar y nada contrarias a la salud del cuerpo, como eran la carne, los huevos, la leche y sus derivados, consumo que estaba prohibido durante la Cuaresma. El permiso perdía validez en la Semana Mayor, cuando el duelo, el sacrificio, la mortificación de los sentidos y de la carne debían normar, por esos pocos días, la vida cristiana para recordar dignamente la muerte de Cristo. ${ }^{18}$

Por su amplísima demanda entre los numerosos glotones del reino fue, sin lugar a dudas, la Bula de Composición la que redituaría los mayores caudales, tanto a la Iglesia, como a la corona.

Asimismo, por el pago de una suma que fluctuaba entre los 900 ducados y los 5000 maravedíes, los grandes ladrones, y los tramposos y demás alimañas a quienes se enlistaba en las

${ }^{17}$ Palafox, Manual, reimpreso en 1826 , p. 91 .

${ }^{18}$ Anónimo, Explicación, 1788; Fernández, Tasación, 1700. 
guerras santas, podían dormir con la conciencia tranquila $y$ olvidarse de las enseñanzas de los mismos padres de la Iglesia que, como San Agustín, aseguraban que "no se perdonaría el pecado sino restituyendo lo ajeno". ${ }^{19}$

La Iglesia, como madre siempre comprensiva e indulgente, se hacía de la vista gorda $y$, mediante este permiso, autorizaba la posesión de lo mal habido, arguyendo que, entre sus amados hijos, existían algunos que no podían hacer tal restitución: unos porque no sabían a quién, otros porque no sabían cuánto y los más porque no podían devolverlo sin una caída notable de su honra.

Con esta manga ancha, la Iglesia también permitía a los eclesiásticos la usura y la posesión de rentas mal habidas; a los abogados, recibir cuantiosas sumas por defender una causa injusta y a los jueces seculares y eclesiásticos, aceptar sin temor la ancestral "mordida"; en tanto que a los escribanos, notarios, secretarios, albaceas y otros rateros similares, los autorizaba a recibir monedas de más, siempre y cuando fingieran ser pobres. Las mujeres que no eran públicamente deshonestas, se podían "componer" asimismo si en alguna ocasión habían recibido joyas o dinero de hombres; pero eso sí, con la condición "moral" de que éstos no tuvieran mujer. ${ }^{20}$

Las indulgencias alcanzaban también por esta vía a los tramposos vinateros, quienes bien podían vender sin temor el vino aguado, en tanto

\footnotetext{
${ }^{19}$ Anónimo, Explicación, 1788.

${ }^{20}$ Rodríguez, Explicación, 1594, pp. 165182.
}

que a los comerciantes se les permitía adulterar impunemente pesas y medidas. Estos verdaderos atracos y otros más se justificaban simplemente con el absurdo y hasta irrisorio ejemplo del Buen Ladrón, que después de haber hurtado cuanto pudo, había sacado en el mismo monte Calvario la Bula de Composición y, gracias a ella, había conseguido el perdón y logrado llegar directamente a la Gloria. ${ }^{21}$

Del mismo tenor era la Bula de Difuntos. Su inteligente promoción se apoyaba en la existencia de dos clases de penas: una eterna con que se pagarían en las llamas del infierno los pecados mortales no confesados y menos aún perdonados, y la pena temporal a cumplir en el purgatorio, desde el momento mismo de la muerte corporal hasta el Juicio Final, por los pecados veniales, o bien por aquellos mortales ya perdonados en la confesión. Esta pena podía disminuirse en vida tratando de satisfacer a la justicia divina con ayunos, vigilias, oraciones, limosnas, cilicios, peregrinaciones y otros sacrificios voluntarios; o con obras pías realizadas en cumplimiento de la penitencia estipulada por el confesor, pues más valía una hora de penitencia en esta vida que cien años de purgatorio en la otra.

Pese a la existencia de estos recursos con que los pecadores podían disminuir su deuda con Dios, muchos cristianos difícilmente podían escapar del fuego del purgatorio: unos por tibieza de espíritu, otros por comodidad y algunos más porque la muerte los alcanzaba sin haber ofrecido cum-

${ }^{21}$ Salazar, Llave, 1738, p. 10. 
plidamente esa satisfacción. De ahí que existieran siempre numerosas almas purgando esa pena temporal y siempre en la ansiosa espera de que algún buen cristiano las librara cuanto antes del fuego purificador. ${ }^{22}$.

Para tal efecto, la Iglesia había establecido dos formas de disminuir tal tormento. Una, que podríamos llamar de largo plazo, consistente en el ofrecimiento por los vivos de diversas obras o sufragios por el descanso de las almas de sus muertos y, la otra, de efectos inmediatos y hasta "garantizados", mediante la compra de la Bula de Difuntos. Con esta Bula, llamada también, por sus nobles fines, Bula de la Misericordia, con el pago de tan sólo cuatro reales por el alma de un español, o de dos si se trataba de un indio, moreno, español pobre o religioso, la Iglesia, además de asegurar el inmediato rescate del alma, prolongaba, como siempre, las diferencias sociales más allá de la muerte. ${ }^{23}$

Con tantas indulgencias como ofrecía la Bula de la Cruzada, podemos imaginar que su venta tuvo un éxito rotundo, sobre todo si tomamos en cuenta, por un lado, ese ancestral temor a la muerte que ha acompañado al género humano a lo largo de la historia $y$, por otro, la habilidad de esa Iglesia negociante y corrupta que rebasaba con creces el ingenio y la pericia de la Banca contemporánea.

Fue tal la demanda de estos codiciados remedios para la salud del alma que llegaron incluso a falsificarse, por lo que la Iglesia y la corona se

${ }^{22}$ Rodríguez, Explicación, 1594, p. 155.

${ }^{23}$ Oviedo, Cruz, 1731, p. 18. vieron precisadas a prevenir a los fieles sobre la circulación de tales falsos, cuyos beneficios quedaban así, de antemano, totalmente nulificados; no obstante, los caudales reunidos por concepto de la Bula llegaron a constituir, durante los siglos XVII y XVIII, uno de los más importantes ramos de la Real Hacienda. ${ }^{24}$

La venta de estos documentos, basada en la existencia de un inagotable tesoro de dispensas, recorrió toda la escala social por su carácter universal, solapando y aun fomentando así, entre los grandes pecadores, toda clase de faltas, como el robo, la gula; la pereza, la usura, la avaricia y otras más que se sumaban a la interminable lista de pecados contra los cuales, supuestamente, era preciso luchar. De esta manera, las indulgencias concedidas por la Bula nos permiten conocer a esa otra Iglesia que, lejos de fomentar y orientar la lucha contra el mal que debía caracterizar la vida del cristiano, vino a nulificarla y a convertirla en un negocio redondo mediante una fácil y lucrativa venta de perdones con el pretexto de preparar a los fieles para la muerte y mantener, a toda costa, la salud del alma.

\section{BIBIIOGRAFÍ}

\section{Fuentes primarias}

-Anónimo, Explicación de la Bula de la Santa Cruzada que para mayor comodidad de los reverendos párrocos y utili-

${ }^{24}$ Weckmann, Mercancía, 1984, p. 385; Anónimo, Explicación, 1788, p. 139. 
dad de los fieles manda a dar a luz el ilustrísimo señor comisario general de la misma Santa Cruzada, Francisco Martín Impresor, Toledo, 1788.

-Calzada, Juan, Tratado de las indulgencias en general $y$ en particular, Imprenta Fraternal, La Habana, 1838, 2 vols.

-Carrillo, Martín, Explicación de la Bula de los Difuntos. En la cual trata las penas y lugar del purgatorio y cómo pueden ser ayudadas las ánimas de los difuntos con las oraciones y sufragios de los vivos. Dedicada a las benditas ánimas del purgatorio, Angelo Tavanno, Zaragoza, 1602

-Crasset, Juan, La dulce y santa muerte, Imprenta de González, Madrid, 1788.

-Fernández de Córdoba, Gonzalo, Tasación última de la limosna que cada persona ba de dar por las bulas que tomaren de vivos, composición, difuntos y lactricinios en las Indias Occidentales o en la Nueva España, becha con autoridad apostólica por Gonzalo Fernández de Córdoba, comisario general de la Santa Cruzada, Herederos dél capitán Juan de Villa Real, Puebla de los Ángeles, 1700.

-Fonte, Pedro de, "Decreto expedido en México el 28 de noviembre de 1821 por el arzobispo Pedro de Fonte disponiendo se suspenda la publicación de la Bula de la Santa Cruzada debido a la separación de México del Reino de España". La Abeja Poblana, vol. II, núm. 4, 1821.

-Guijarro, Francisco, Buen uso de la teología moral según la doctrina y espiritu de la Iglesia, Benito Monfort, Valencia, 1792, 3 vols.

-Oviedo, Juan Antonio de, La cruz ligera y suave para los vivos, lúcida y resplandeciente para los muertos, Impresa por José Bernardo de Hogal, México, 1731.

-Palafox y Mendoza, Juan, Manual para la precisa, pronta y fácil administración de los sacramentos, reimpreso en la oficina del ciudadano Pedro de la Rosa, Puebla, 1826.
-Rodríguez Lusitano, Manuel, Explicación de la Bula de la Santa Cruzada y de las cláusulas de los jubileos y confesionarios que ordinariamente suele conceder Su Santidad, muy provechosa para predicadores, curas y confesores, así como en los reinos donde no bay Bula, Juan Escalante, Salamanca, 1594.

-Salazar, Juan de, Llave maestra para abrir el cielo que en la Santa Bula de la Cruzada discurrió y predicó el día 1 de diciembre del año de 1737. En la santa iglesia catedral de México con asistencia del ilustrísimo y excelentísimo señor virrey don Juan Antonio Vizarrón y Eguiarreta, José Bernardo de Hogal, ministro e impresor del Real y Apostólico Tribunal de la Santa Cruzada en Nueva España, México, 1738.

-Venegas, Alejo, Agonía del tránsito de la muerte, con los avisos y consuelos que cerca de ella son provechosos, dirigida a la muy ilustre señora doña Ana de la Cerda, condesa de Mélito, s. e., Alcalá de Henares, 1565.

\section{Fuentes secundarias}

-Carreño, Alberto María, Cedulario de los siglos XVI y XVII. El obispo don Juan de Palafox y Mendoza $y$ el conflicto con la Compañía de Jesús, Ediciones Victoria, México, 1947.

-Le Goff, Jacques, La baja edad media, Siglo XXI Editores, México, 1974 (Historia Universal Siglo XXI, vol. 11).

-Mansutti Rodríguez, A., Catálogo del ramo de Bulas y Santa Cruzada, Archivo General de la Nación, México, 1979' (Guías y Catálogos, 41).

-Recopilación de leyes de los reinos de Indias, Ediciones Cultura Hispánica, Madrid, 1973, 4 vols.

-Weckmann, Luis, La berencia medieval en México, El Colegio de México, México. 1984,2 vols. 


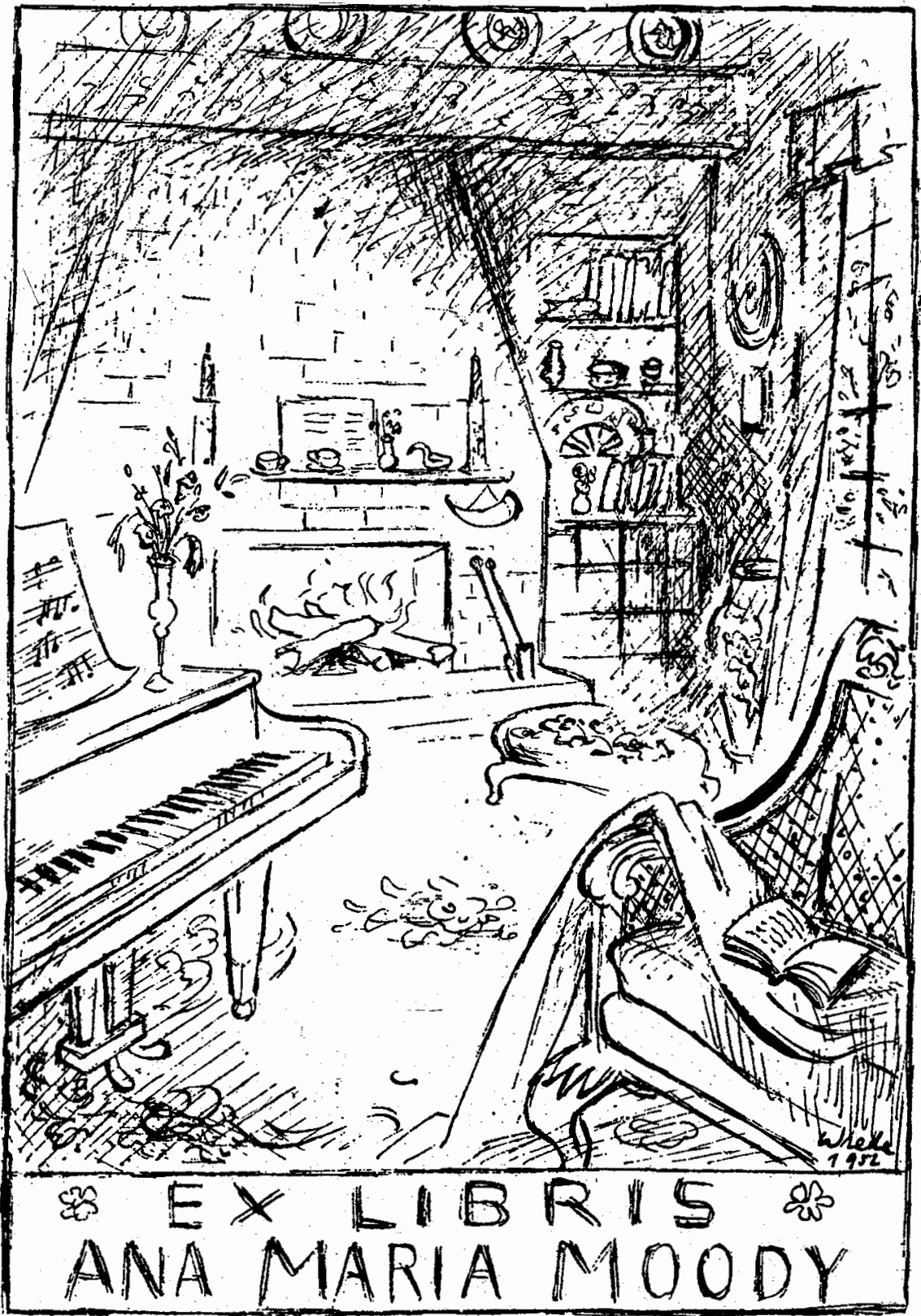

